\title{
Non-hereditary risk factors associated with pancreatic cancer: a focus on obesity and diabetes
}

\section{Céline Tiffon* \\ Independent Researcher, France}

The number of new cancer diagnoses is projected to increase by over $20 \%$ in Europe by 2035 , and cancer is expected to become the leading cause of death worldwide. Accepted risk factors for cancer include smoking, alcohol consumption, diet (insufficient consumption of fruit, vegetables, fiber, and dairy products and consumption of red and processed meat), obesity, and lack of physical activity. Pancreatic cancers, about $85 \%$ of which are pancreatic ductal adenocarcinomas, are highly lethal, with a 5-year survival rate of only $7 \%$ [1]. A greater understanding of the risk factors for pancreatic cancer are urgently required to develop preventative and early detection strategies.

Nearly $30 \%$ of the world's population is now overweight or obese [2,3]. Furthermore, the prevalence of obesity in children has increased dramatically over recent decades, and obesity is a major health concern and priority in both children and adults. Excess body weight and diabetes have been recognized as two non-hereditary risk factors for pancreatic cancer, and excess body weight and obesity underpin inflammatory and metabolic diseases including insulin resistance and type 2 diabetes mellitus. Obesity can be regarded as a state of chronic low-grade inflammation, since adipose tissue actively secretes inflammatory and immune mediators. Hypertrophic adipocytes produce proinflammatory cytokines such as interleukin-6 (IL-6) and tumor necrosis factor-a (TNF-a), which have local effects on different cell types, inducing a state of inflammation and systemic insulin resistance [4]. Serum markers of inflammation (IL-6, TNF- $\alpha$, leptin) are elevated in overweight and obese children and adults.

The pro-inflammatory state induced by obesity may increase pancreatic cancer risk via a number of mechanisms [5]. Cytokines and inflammatory mediators such as TNF-a, IL-6, IL-8, and IL-10 are thought to participate in the initiation and progression of cancer [6], including pancreatic cancer [7], and inflammation also affects immune surveillance and responses to therapy [8]. Inflammation caused by diet-induced obesity triggers increased K-Ras activity, which can be an underlying cause of pancreatic tumorigenesis. Lin et al. [9] identified a critical role for IL-29 in obesity-induced adipose tissue inflammation and insulin resistance. IL-29 and its receptor were found to be expressed in adipose tissue isolated from obese patients, and IL29 stimulated adipocyte inflammation by increasing inflammatory cytokine production such as IL- 8 and IL- $1 \beta$. This finding makes IL-29 a novel candidate target for treating obesity and insulin resistance in patients with metabolic disorders.

Adipocytes also act in an endocrine manner to send and receive signals that modulate a number of processes including appetite, energy expenditure, and insulin sensitivity. Food intake is regulated by the interaction of several neurotransmitters such as leptin, acetylcholine, serotonin, and dopamine, cytokines, and insulin and insulin receptors in the brain. In addition, exercise promotes anti-inflammatory reactions that favor biochemical events in the brain that suppress appetite. Lee, Lee and Choue [10] discussed the influence of dietary factors on inflammation associated with obesity and suggested that optimal nutrition includes vitamins, minerals, flavonoids, and polyunsaturated fatty acids (PUFAs), which play essential roles in immunity. These nutrients are anti-inflammatory and therefore beneficial, perhaps even early in life. For instance, Das (2001) [11] suggested supplementing infant formulas with long-chain polyunsaturated fatty acids (LCPUFAs), as these fatty acids might play an important role during the critical stages of brain development, in brain function, and in suppressing inflammation, which is not only of importance during early childhood but many years later.

Adipose tissue is also implicated in the development of chronic metabolic diseases such as diabetes, especially type 2 diabetes mellitus, and a number of mechanisms have been hypothesized linking diabetes and cancer such as insulin resistance, hyperinsulinemia, hyperglycemia, and increased inflammatory processes. The same pro-inflammatory cytokines increased in obesity are also increased in patients with type 2 diabetes and are implicated in carcinogenesis including TNF- $\alpha$, IL-6, leptin, C-reactive protein (CRP), and adiponectin, a cytokine produced by adipose tissue and associated with insulin sensitivity and therefore a cytokine with protective effects against the development of type 2 diabetes (Wu et al., 2016; Saeedi et al., 2019) [12,13].

As well as obesity contributing to cancer risk via inflammatory pathways, individual foods and drinks have been shown to have pro- or anti-inflammatory effects, with vegetables, fruit, and oily fish classical examples of anti-inflammatory foods. Therefore, dietary supplements have been examined in cancer risk and therapy. González et al. (2016) [14] reported that high-dose intravenous vitamin C can be used in the management of pancreatic cancer patients and improve quality of life. Active hexose correlated compound (AHCC) is a dietary supplement with a well-known immune stimulating effect, and there is a report of AHCC use maintaining remission in a breast cancer patient [15] Ginseng extract contains numerous phytochemicals that have significant pharmacological activities, and Cai, Zhang and Huang (2019) [16] reviewed the data showing that ginseng extract and its constituents are promising candidates for cisplatin toxicity prevention and the reversal of resistance. Intermittent fasting has also been recognized as an anticancer strategy. Durán et al. (2018) [17] demonstrated the effectiveness

${ }^{*}$ Correspondence to: Céline Tiffon, Ph.D, Independent Researcher, 50 rue des vignes 92000 Nanterre, Hauts-de-Seine, France, Tel: +33(0)689109162, E-mail: celine.tiffon@gmail.com

Received: April 04, 2020; Accepted: April 14, 2020; Published: April 17, 2020 
of intermittent starvation as a metabolic cancer therapy that may predict improve outcomes in combination with chemotherapeutics.

In terms of ingestion of toxins that might contribute to pancreatic cancer risk, bisphenol A (BPA) and phthalates are endocrine disrupting-chemicals (EDCs) that are increasingly thought to play a role in carcinogenesis and can promote weight gain and obesity by interfering with the action of neurotransmitters and signaling pathways in the brain. Both BPA and phthalates contaminate food and water and are obesogenic. Pregnancy and childhood are sensitive windows of susceptibility to toxins, and numerous studies have suggested that these chemicals impact the development of metabolic diseases, e.g. obesity and diabetes, even many years after exposure, with adipocytes and pancreatic $\beta$-cells particular targets. Filardi et al. (2020) [18] highlighted the effects of BPA and phthalates on metabolic diseases, and Papalou et al. (2019) [19] presented evidence on how these substances can perturb human metabolism, causing an altered balance favoring obesity and metabolic diseases. Finally, the immune system constitutes another target of EDC action, as for natural hormones [20].

A considerable proportion of cancer cases could be avoided, and many risk factors are preventable, not least obesity and its associated diabetes. For less avoidable risk factors such as endocrine disruptors, which we may be exposed to daily, exposure needs to be minimized to prevent cancer, sometimes many years later. Prevention and education, particularly for young people and pregnant women, are urgently required.

Conflicts of Interest: The author declares no competing interests.

\section{References}

1. Ryan DP, Hong TS, Bardeesy N (2014) Pancreatic adenocarcinoma. N Engl J Med 371: 1039-1049. [Crossref]

2. Chooi YC, Ding C, Magkos F (2019) The epidemiology of obesity. Metabolism 92: 6-10. [Crossref]

3. Di Cesare M, Sorić M, Bovet P, Miranda JJ, Bhutta Z, et al. (2019) The epidemiological burden of obesity in childhood: a worldwide epidemic requiring urgent action. $B M C$ Med 17: 212. [Crossref]

4. Shoelson SE, Herrero L, Naaz A (2007) Obesity, inflammation, and insulin resistance. Gastroenterology 132: 2169-2180. [Crossref]
5. Krishna SG, Hussan H, Cruz-Monserrate Z, Conteh LF, Mumtaz K, et al. (2017) A review of the impact of obesity on common gastrointestinal malignancies. Integr Cancer Sci Ther 4: 1000223. [Crossref]

6. Landskron G, De la Fuente M, Thuwajit P, Thuwajit C, Hermoso MA (2014) Chronic inflammation and cytokines in the tumor microenvironment. J Immunol Res : 149185. [Crossref]

7. Shadhu K, Xi C (2019) Inflammation and pancreatic cancer: An updated review. Saudi J Gastroenterol 25: 3-13. [Crossref]

8. Grivennikov SI, Greten FR, Karin M (2010) Immunity, inflammation, and cancer. Cell 140: 883-899. [Crossref]

9. Lin TY, Chiu CJ, Kuan CH, Chen FH, Shen YC, et al. (2019) IL-29 promoted obesityinduced inflammation and insulin resistance. Cell Mol Immunol 17: 369-379. [Crossref]

10. Lee H, Lee IS, Choue R (2013) Obesity, inflammation and diet. Pediatr Gastroenterol Hepatol Nutr 16: 143-152. [Crossref]

11. Das UN (2001) Is obesity an inflammatory condition? Nutrition 17: 953-966. [Crossref]

12. Wu Y, Liu Y, Dong Y, Vadgama J (2016) Diabetes-associated dysregulated cytokines and cancer. Integr Cancer Sci Ther 3: 370-378. [Crossref]

13. Saeedi P, Petersohn I, Salpea P, Malanda B, Karuranga S, et al. (2019) Global and regional diabetes prevalence estimates for 2019 and projections for 2030 and 2045 Results from the International Diabetes Federation Diabetes Atlas ( $9^{\text {th }}$ Edn). Diabetes Res Clin Pract 157: 107843. [Crossref]

14. González MJ, Berdiel MJ, Miranda-Massari JR, López D, Duconge J, et al. (2016) High dose intravenous vitamin $\mathrm{c}$ and metastatic pancreatic cancer: Two cases. Integr Cancer Sci Ther 3: 1000219.

15. Wakame K, Takanari J, Sato A, Shirakawa S, Komatsu K (2017) Long-term administration of active hexose correlated compound as a dietary supplement to a patient after breast cancer surgery and chemotherapy: A case report. Integr Cancer Sci Ther 4: 1000226.

16. Cai J, Zhang Q, Huang H (2019) Ginseng extract and its constituents alleviate cisplatin toxicity and reverse cisplatin resistance. Integr Cancer Sci Ther 6: 1000326.

17. Durán I, Pomuceno-Orduñez JP, Martín RR, Silva E, Montero S, et al. (2018) Glucose starvation as cancer treatment: Thermodynamic point of view. Integr Cancer Sci Ther 5: 1000276.

18. Filardi T, Panimolle F, Lenzi A, Morano S (2020) Bisphenol A and Phthalates in Diet: An Emerging Link with Pregnancy Complications. Nutrients 12: E525. [Crossref]

19. Papalou O, Kandaraki EA, Papadakis G, Diamanti-Kandarakis E (2019) Endocrine Disrupting Chemicals: An Occult Mediator of Metabolic Disease. Front Endocrinol (Lausanne) 10: 112. [Crossref]

20. Nowak K, Jabłońska E, Ratajczak-Wrona W (2019) Immunomodulatory effects of synthetic endocrine disrupting chemicals on the development and functions of human immune cells. Environ Int 125: 350-364. [Crossref]

Copyright: (C2020 Tiffon C. This is an open-access article distributed under the terms of the Creative Commons Attribution License, which permits unrestricted use, distribution, and reproduction in any medium, provided the original author and source are credited. 